82

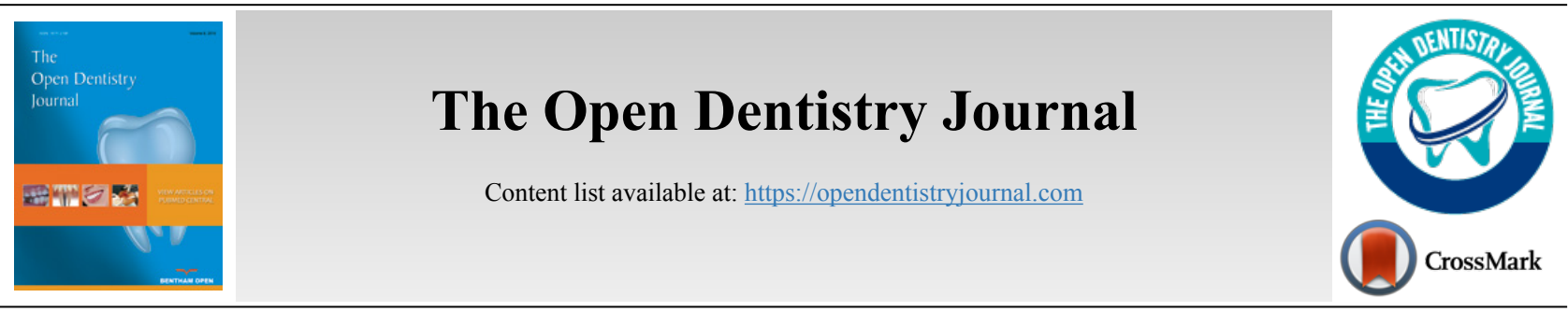

RESEARCH ARTICLE

\title{
The Role of Parathyroid Hormone in Alveolar Bone Resorption on Postmenopausal Women
}

Susi R. Puspitadewi ${ }^{1}\left(\mathbb{D}\right.$, Lindawati S. Kusdhany ${ }^{2, *}$, Sri Lelyati C. Masulili ${ }^{3} \mathbb{E}$, Pitu Wulandari ${ }^{1}$, Hanna B. Iskandar $^{4}$ and Elza I. Auerkari ${ }^{5}$

${ }^{1}$ Faculty of Dentistry, University of Indonesia, Jakarta, Indonesia.

${ }^{2}$ Department of Prosthodontics, Faculty of Dentistry, University of Indonesia, Jakarta, Indonesia.

${ }^{3}$ Department of Periodontics, Faculty of Dentistry, University of Indonesia, Jakarta, Indonesia.

${ }^{4}$ Department of Dento-maxillofacial Radiology, Faculty of Dentistry, University of Indonesia, Jakarta, Indonesia.

${ }^{5}$ Department of Oral Biology, Faculty of Dentistry, University of Indonesia, Jakarta, Indonesia.

\begin{abstract}
:
Background:

Postmenopausal women exhibit reduced bone mineralization, which causes bone resorption, including that of alveolar bone. Parathyroid hormone has been shown to play a role in alveolar bone resorption.

Objective:

This study aims to analyze relationships between parathyroid hormone and other factors that may contribute to alveolar bone resorption in postmenopausal women.

Methods:

This cross-sectional study included 82 postmenopausal women aged 50-74 years, who resided in Central and East Jakarta, Indonesia. Subjects data were obtained through questionnaires, dental examinations, and blood collection for the examination of parathyroid hormone levels by enzyme-linked immunosorbent assay and using panoramic radiography to measure bone resorption.

Results:

Spearman correlation analysis showed a significant correlation between parathyroid hormone level $(p=0.005)$ and extent of alveolar bone resorption, but age $(p=0.292)$, menopausal duration $(p=0.244)$, and number of missing teeth $(p=0.517)$ were not significantly correlated with the extent of alveolar bone resorption.

\section{Conclusion:}

Various factors play a role in the mechanism of bone resorption, so knowing the role of each factor is expected to reduce the effects of alveolar bone resorption that occurs in postmenopause. Among the factors investigated in this study, the parathyroid hormone was the sole factor correlated with postmenopausal alveolar bone resorption.
\end{abstract}

Keywords: Age, Alveolar bone resorption, Postmenopausal, Parathyroid hormone, Panoramic radiography, Teeth.

\section{Article History} Received: October 30, 2019

Revised: January 07,2020

Accepted: January 13, 2020

\section{INTRODUCTION}

Parathyroid Hormone (PTH) is secreted by the parathyroid gland, and this hormone plays an important role in calcium

\footnotetext{
* Address correspondence to this author at the Department of Prosthodontics, Faculty of Dentistry, University of Indonesia, Jakarta, Indonesia;

Tel: +6281284883763; Fax: +622131931412;

Email: lindaskusdhany@gmail.com
}

homeostasis and bone remodeling. Parathyroid hormone maintains blood plasma levels of calcium by promoting calcium release from bone as needed; in such cases, remodeling in bone shifts toward resorption rather than bone formation. Bone remodeling is a constant and coordinated growth of the mineral bone matrix that occurs as a response to mechanical and endocrine stimuli; it is carried out by osteoclasts (resorption) and osteoblasts (formation). In normal 
homeostatic conditions, bone resorption is equivalent to bone formation [1 - 3].

Alveolar bone comprises a unique network of several parts that function to support the teeth. The alveolar process contains an outer plate of cortical bone, deep socket of thick compact bone, and trabecular bone [1,2]. Alveolar bone is derived from the intra-membrane and undergoes continuous remodeling by osteoblasts and osteoclasts. During the aging process, the alveolar bone becomes osteoporotic with rough and jagged wall sockets, which contain a small number of lacuna cells and marrow tissue infiltrated by fat tissue, thus reducing support for teeth [2].

In women, the hormonal disorder is important during the climacteric period, which comprises the premenopausal, menopausal, and postmenopausal periods. In the postmenopausal period, changes in physiological and biochemical mechanisms occur, which can affect bone mineralization and metabolism. The reduction of estrogen in the postmenopausal period causes increased bone resorption [1, 3]. Women lose $3 \%$ of their bone mineral density every year after the onset of menopause; this causes osteopenia and eventual osteoporosis. Mohammad et al. showed that postmenopausal women with normal bone density have an average of 6.8 tooth loss, whereas women suffering from osteopenia have an average of 10.5 teeth and osteoporosis women have an average of 16.5 teeth tooth loss [4]. In addition to estrogen, PTH plays a role in the occurrence of osteoporosis in the postmenopausal period by controlling extracellular calcium and phosphate levels through regulation of intestinal resorption, renal excretion, and balance between extracellular fluid and ions in the bone $[1,3]$.

Estrogen deficiency causes the loss of PTH function as a result of calcium loss and increasing PTH levels. Increased levels of PTH cause calcium to be released from the bone, resulting in increased levels of calcium in the blood. Calcium ions are the most essential component of the calcium process. The process of bone turnover is regulated by the relationship that occurs between hormones and other factors like calcium and vitamin D. PTH levels control serum concentrations of calcium. Calcium deficiency and malabsorption cause hormonal imbalances, leading to bone disorders such as osteopenia and osteoporosis. The incidence of osteoporosis increases in the postmenopausal period $[1,4,5]$.

Moreover, Oluboyo et al. showed that in the postmenopausal period, there are increased levels of PTH, calcium, and phosphate, whereas the level of estrogen is reduced [1]. Aging is associated with progressive bone loss in men and women. However, currently, there are bone changes that cause osteoporosis which often occurs in women, but this has not been described in men. Changes in bone turnover in men are influenced primarily by bone metabolic diseases whose incidence is higher in women $[6,7]$.

Menopause is a physiological condition characterized by the cessation of the menstrual cycle and causes irreversible hormonal changes. At around 50 years old, there are some signs such as hot flush, depression, irritability, loss of concentration, dry skin, and osteoporosis. In most people, osteoporosis is considered a process that is associated with tooth loss in elderly individuals [8 - 10]. Bone changes due to osteoporosis are associated with high alveolar peak loss and tooth loss in women after menopause. Estrogen deficiency after menopause is considered to be a possible cause related to tooth loss due to low bone density. Estrogen provides a protective effect against tooth loss and bone loss, so estrogen deficiency will affect the reduction of bone mineral density [10]. In fact, various important factors related to tooth loss and osteoporosis such as age, low level of education, chronic illness, smoking, alcohol use, oral hygiene, and unhealthy diet [11].

Loss of teeth due to extraction actions may result in changes to the alveolar bone. An individual who has a significant loss of teeth without denture usage can experience nutritional deficiencies due to an inability to chew food. Severe alveolar bone resorption is a vital problem in dental treatment: alveolar bone is needed to support retention, stabilization, and denture masticatory function [8,9]. This study aimed to analyze the relationships between factors that contribute to bone resorption (e.g., age, duration of menopause, number of lost teeth, and PTH) and the extent of alveolar bone resorption.

\section{MATERIAL AND METHODS}

This cross-sectional study was conducted from May 2018 to November 2018 among postmenopausal subjects aged 50 until 75 years old in Central Jakarta and East Jakarta, Indonesia. The study received ethical approval from the Research Ethics Committee of Dentistry (KEPKG), Faculty of Dentistry, Universitas Indonesia. All subjects provided written informed consent to be included in the study. Postmenopausal women included in this study were women who naturally stopped menstruating for 12 months [12]. Women excluded from this study were those who were postmenopausal due to the removal of the uterus or both ovaries, those receiving hormone replacement therapy, those with systemic diseases such as diabetes mellitus or cancer, and those who were smokers and or consuming alcohol.

Subjects' demographic characteristics and menopause data were obtained through interviews. Oral health conditions were assessed, and the numbers of missing teeth were recorded for each subject. Blood samples were collected from subjects' veins and then centrifuged 1,000-2,000 x g for 10 minutes and stored at $-80^{\circ} \mathrm{C}$; samples were defrosted at room temperature before further analysis. PTH concentrations were measured using an enzyme-linked immunosorbent assay (AIA-PACK ${ }^{\mathrm{TM}}$ Intact PTH Assay Kit, Tosoh Bioscience). All assays were performed by the Integrated Laboratory Faculty of Medicine, University Indonesia.

Measurement of the panoramic mandibular index (PMI) was performed to measure the resorption of mandibular alveolar bone. The PMI is a measurement of mandibular osteoporosis that represents the ratio of the thickness of the mandibular cortex to the distance between the inferior border from the mental foramen to the mandibular cortex (Fig. 1). The method was as follows: 1 . Draw a line parallel to the long axis of the mandible and perpendicular to the inferior border of the mandible. This perpendicular line intersects the inferior foramen mentalist boundary 2. Measure the distance from the 
inferior border of the mandibular cortex to the inferior edge of the mental foramen 3. At the mandibular cortex, the same measurement is performed on both sides of the jaw. The greatest extents of resorption were measured on both sides of the jaw. Measurements (in $\mathrm{mm}$ ) were performed using digital calipers; PMI $\geq 0.30 \mathrm{~mm}$ was regarded as normal $[13,14]$.

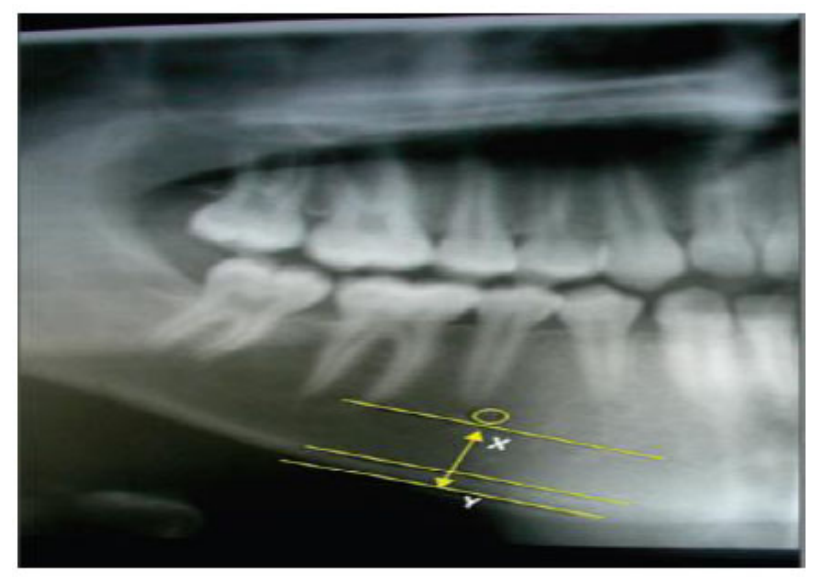

Fig. (1). Cropped panoramic radiograph showing the left body of the mandible in the region of the mental foramen $(\mathbf{M})$. A line $(\mathbf{X})$ was drawn from the midpoint of the foramen to the lower border of the mandible, at right angles to the tangent (Y) to the lower border at this point. The width of the cortical bone at the lower border was measured along the line (X) from the lower mandibular border to the inner edge of the cortex.

The cutoff values of bone resorption, age, menopausal duration, number of missing teeth and parathyroid hormones of these variables are based on reference and median. Bivariate analysis was performed using Spearman's correlation analysis test; A $p$-value of less than 0.05 was considered significant in all statistical analyses. Data were elaborated using the special statistical program SPSS.

\section{RESULTS}

This study included 82 subjects, with the mean age of 60.23 years old. The mean level of PTH and the extent of bone resorption were $42.28 \mathrm{pg} / \mathrm{mL}$ and $0.277 \mathrm{~mm}$, respectively (Table 1).

Table 1. Subjects' characteristics.

\begin{tabular}{|c|c|c|c|}
\hline $\begin{array}{c}\text { Postmenopausal Women (n }= \\
\text { 82) }\end{array}$ & Mean (SD) & Minimum & Maximum \\
\hline Age (years) & $60.23(6.49)$ & 50 & 74 \\
\hline Menopausal duration (years) & $11.52(7.05)$ & 1 & 34 \\
\hline Number of missing teeth & $9.34(8.08)$ & 0 & 32 \\
\hline $\begin{array}{c}\text { Parathyroid hormone level } \\
\text { (pg/mL) }\end{array}$ & $42.48(29.64)$ & 5 & 144.50 \\
\hline Extent of bone resorption (mm) & $0.277(0.60)$ & 0.148 & 0.418 \\
\hline
\end{tabular}

SD, standard deviation.

Table 2 shows the subjects' characteristics based on bone resorption: the majority of subjects aged $\geq 60$ years $(52.54 \%)$ had bone resorption, whereas those aged $<60$ years did not $(47.46 \%)$. Subjects with menopausal duration $>5$ years (79.66\%) had more bone resorption than subjects with a menopausal duration of $\leq 5$ years $(20.34 \%)$. Subjects who lost fewer than six teeth exhibited less bone resorption (42.37\%), and the majority of subjects with bone resorption had PTH levels $<75 \mathrm{pg} / \mathrm{mL}$ (88.14\%) (Table 2).

Table 2. Subjects' characteristics based on bone resorption.

\begin{tabular}{|c|c|c|c|c|}
\hline \multirow{2}{*}{$\begin{array}{c}\text { Postmenopausal Women } \\
(\mathbf{n}=\mathbf{8 2})\end{array}$} & \multicolumn{2}{|c|}{$\begin{array}{c}\text { Normal Bone } \\
(\mathbf{0 . 3})\end{array}$} & \multicolumn{2}{c|}{$\begin{array}{c}\text { Bone } \\
\text { Resorption(<0.3) }\end{array}$} \\
\cline { 2 - 5 } & $\mathbf{n}$ & $\mathbf{\%}$ & $\mathbf{n}$ & $\mathbf{\%}$ \\
\hline Age & & & & \\
\hline$<60$ years & 12 & 52.17 & 28 & 47.46 \\
\hline$\geq 60$ years & 11 & 47.83 & 31 & 52.54 \\
\hline Menopausal duration & & & & \\
\hline$\leq 5$ years & 8 & 34.78 & 12 & $20: 34$ \\
\hline$>5$ years & 15 & 65.22 & 47 & 79.66 \\
\hline Number of missing teeth & & & & \\
\hline$<6$ & 10 & 43.48 & 25 & 42.37 \\
\hline$\geq 6$ & 13 & 56.52 & 34 & 57.63 \\
\hline Parathyroid hormone level & & & & \\
\hline$<75 \mathrm{pg} / \mathrm{mL}$ & 21 & 91.30 & 52 & 88.14 \\
\hline$\geq 75 \mathrm{pg} / \mathrm{mL}$ & 2 & 8.70 & 7 & 11.86 \\
\hline
\end{tabular}

Spearman correlation analysis revealed no significant correlations between bone resorption and each of the following: age, menopausal duration, and the number of missing teeth $(\mathrm{p}>0.05)$. However, there was a statistically significant correlation between bone resorption and PTH level $(\mathrm{p}=0.005)$; the correlation was weakly negative $(-0.304)$ (Table 3).

Table 3. Spearman correlations between bone resorption and other factors in this study.

\begin{tabular}{|c|c|c|}
\hline \multirow{2}{*}{ Postmenopausal Women $(\mathrm{n}=82)$} & \multicolumn{2}{|c|}{$\begin{array}{c}\text { Extent of Bone Resorption } \\
(\mathrm{mm})\end{array}$} \\
\hline & $\begin{array}{c}\text { Correlation } \\
\text { coefficient }\end{array}$ & $p$ \\
\hline Age (years) & -0.118 & 0.292 \\
\hline Menopausal duration (years) & -0.130 & 0.244 \\
\hline Number of missing teeth & -0.073 & 0.517 \\
\hline Parathyroid hormone level (pg/mL) & -0.304 & $0.005^{*}$ \\
\hline
\end{tabular}

\section{DISCUSSION}

The aging process is characterized by changes in bodily structure and function. Problems arising in menopause are often associated with aging. Lifestyle factors, demographics, and attitudes affect women's perceptions of menopause. Most women complain of postmenopausal symptoms, but some do not feel the symptom. One symptom that is often complained after menopause is a problem related to bone $[1,2]$. By 2050 , the population aged $\geq 65$ years will have increased to 1.5 billion, from 323 million in the current time. Increasing age will cause reduced bone formation. This is largely due to the shift from osteoblastogenesis to being more dominant to 
adipogenesis in the bone marrow which has a lipotoxic effect that can affect bone formation and mineralization. As a result of the aging process, the bone will experience a setback in its composition, structure, and function which predisposes to osteoporosis $[2,15]$. Osteoporosis is a disease that has the risk of increasing bone fracture due to decreased bone mass in postmenopausal women. Fractures due to osteoporosis become important epidemiological as well as socio-medical problem [2, $16]$.

The most common fractures in the elderly are fractures of the spine, hip, forearm and proximal humerus. Fractures of the hip are the most common cause of morbidity and mortality. More than one-third of women aged 60 to 70 years have osteoporosis. Osteoporosis is a silent disease that causes low bone density, which can ultimately lead to fractures [8]. In this study, the subjects were aged 50 to 74 years, in accordance with the approach used in a study by Esen et al. With increasing age, bone balance becomes negative, such that bone resorption is more active than bone formation [17]. With increasing age, bone balance becomes negative, such that bone resorption is more active than bone formation. The overall results of age-related bone changes include cortical thinning, increased cortical porosity, trabecular thinning, and loss of trabecular connectivity; these conditions cause reduced bone quality and bone strength $[15,18]$.

The maximum duration of menopause was 34 years in this study. In women, there is a phase of accelerated bone loss after menopause due to estrogen deficiency. Estrogen plays a role in the development of secondary sexual characteristics in women, as well as in regulating the menstrual cycle. When estrogen is reduced, the menstrual cycle stops and menopause occurs [1]. After bone mass reaches its peak, bone turnover occurs more slowly, such that bone remodeling primarily comprises bone resorption, rather than bone formation. After menopause, there is increased bone resorption due to estrogen deficiency, thus accelerating bone loss. The extended duration of menopause tends to reduce bone mineral density and bone resorption [19, 20]. Furthermore, Nurumal et al. demonstrated that increased length of menopause and increased age reduce bone mineral density [21].

The alveolar bone grows at a speed concomitant with that of tooth eruption. Each tooth binds to the periodontal ligament fibers surrounding it. Alveolar bone volume is determined by tooth shape, tooth axis during eruption, and tooth inclination. When a tooth is lost, the buccal and lingual portions of alveolar bone exhibit increased vulnerability, and the level of bone is reduced by approximately $2 \mathrm{~mm}$ after tooth loss [9]. In this study, the mean number of teeth lost by the subjects was 9.34 (standard deviation $=8.08$ ). The process of bone resorption leads to a narrower and shorter ridge, which more often affects the palatal/lingual portions of alveolar bone; thus, defects due to loss of teeth are more severe. This condition is worsened when a considerable amount of alveolar bone is lost. Tooth loss is followed by bone resorption in three dimensions, thus inhibiting dental restorations $[9,22]$.

Dual-energy X-ray absorption (DXA) is a standard in evaluating bone mineral density, but various panoramic radiographic index studies look for predictors in examining reduced bone density in screening patients. The examination of bone resorption in this study was carried out using the panoramic mandibular index. According to Calciolari et al., the panoramic mandibular index can assist in detecting patients who are at risk of decreasing bone mineral density [14]. Singh et al. showed that there is a correlation between PMI and MCI with DXA Bone mineral density. PMI and MCI are economical and reliable screening tools in detecting osteoporosis and osteopenia in patients, so for dentists, the use of this tool can help improve the prognosis of care and modify the treatment plan undertaken because the availability of this tool is universal [23]. Bone resorption is irreversible, chronic, and cumulative. Resorption occurs within the first year after tooth extraction and occurs at the most rapid rate during the first 3 months of the year [22]. However, this study found no relationship between the number of lost teeth and the extent of alveolar bone resorption $(p=0.517)$; this result suggests that, regardless of the factors that cause bone resorption, the essential characteristics of alveolar bone play an essential role. In patients with adequate alveolar bone quantity and quality at the time of tooth loss, less visible bone resorption has been observed [22]. Notably, Alves et al. demonstrated that tooth loss was not significantly affected by menopause [24].

Serum calcium is elevated in postmenopausal women due to the aging process. Reduced estrogen in postmenopausal women is accompanied by increased serum levels of PTH, which leads to the release of calcium ions from bones, thus increasing serum calcium levels. High levels of serum calcium are present in women who are at the beginning of menopause; however, these levels decrease with age, due to increased intestinal calcium absorption [3, 5].

Increased calcium and phosphate levels begin at the beginning of the increase in PTH levels because phosphorus and calcium are mainly regulated by PTH hormone and the active form of vitamin D. Excessive activity of the parathyroid gland will cause the absorption of calcium salts in the bone to increase resulting in hypercalcemia in extracellular fluid [25, 26]. Parathyroid hormone increases calcium reabsorption in the kidney, and calcitriol production increases calcium absorption in the intestine. Parathyroid hormones and calcitriol are the main regulators of calcium balance. PTH is largely responsible for serum calcium minute by minute, while calcitriol maintains serum calcium concentrations day by day. Calcitriol together with PTH plays a role in stimulating osteoclasts in bone resorption. Calcitriol is needed for osteoclast differentiation from precursor mononuclear cells. Interestingly, regardless of the presence of PTH, calcium release from the bone is reduced, thus decreasing serum calcium levels $[25,26]$.

In this study, there was a significant, weakly negative correlation between PTH and the extent of bone resorption ( $r=$ $-0.304 ; p=0.005$ ). This finding may be related to the PTH levels below $75 \mathrm{pg} / \mathrm{mL}$ in most subjects; this number remained in the normal range, but bone resorption was observed in the majority of subjects. Recently, researchers have shown that the intermittent injection of osteoporosis patients with PTH amino acids 1-34 (teriparatide) can increase bone mass and bone formation while reducing the risk of fractures. This indicates the other effects of PTH, which may further reduce the 
occurrence of bone resorption [27, 28]. Khosla et al. stated that estrogen deficiency is responsible not only for increasing bone turnover in early postmenopausal but also indirectly playing a role in secondary hyperparathyroidism and increased bone turnover found in late postmenopausal. Serum estrogen residual levels are very important in determining bone resorption in the postmenopausal period [29].

Fuller et al. showed that PTH could increase bone resorption by inducing osteoclast differentiation; this process depended on the response of stromal cells and cannot be regarded as the effect of hormones as osteoclast precursors [30]. Wang et al. showed that intermittent PTH treatment could improve the ability to repair tissue damage and symptoms of periodontitis [31]. PTH will bind to the PTH receptor in the mesenchymal stem cell (MSC), and submit the MSC to osteoblasts to help bone formation [32]. The function of PTH is mediated by paired $G$ protein receptors called PTH1R, the PTH-1 receptor, which regulates skeletal development, bone turnover, and mineral ion homeostasis. Parathyroid hormone therapy (1-34) can increase gene expression associated with osteoblasts and cell mineralization capacities and supports the future application of PTH in periodontitis therapy. This research shows that PTH is like a double-edged knife and has a very high and complicated molecular mechanism of PTH [31]. This is in line with Kim et al. who showed that intermittent PTH therapy will reduce alveolar bone loss and sclerostin expression in osteocytes, but can increase osteoid formation and mineralization, which shows that intermittent PTH therapy can reduce alveolar bone loss aggravated by diabetes by inducing bone formation [33].

Examination of bone resorption is essential because of the need to determine when the bone mass has reached a critical level; this information can help clinicians to determine the appropriate time to assess postmenopausal women for osteoporosis $[20,34]$. The limitations of this study were that it did not include analyses of calcium levels or levels of other hormones such as estrogen; thus, additional research is needed to determine whether these factors contribute to bone resorption and there is no periodontal examination of the periodontal condition on the subject and to further our understanding of the relationship between periodontal status and tooth loss, longitudinal studies are needed.

\section{CONCLUSION}

Various factors play a role in the mechanism of bone resorption, so knowing the role of each factor is expected to reduce the effects of alveolar bone resorption that occurs in postmenopause. Among the factors investigated in this study, the parathyroid hormone was the sole factor correlated with postmenopausal alveolar bone resorption. Further studies are needed to determine the role of PTH in bone resorption in postmenopausal women.

\section{LIST OF ABBREVIATIONS}

$$
\begin{array}{ll}
\text { PMI } & =\text { Panoramic Mandibular Index } \\
\text { PTH } & =\text { Parathyroid Hormone }
\end{array}
$$

\section{ETHICS APPROVAL AND CONSENT TO PARTI- CIPATE}

This study was approved by the Dental Research Ethics Commission (KEPKG), Faculty of Dentistry, University of Indonesia, Indonesia with approval number 68/ethical approval/FKG UI/VIII/2018.

\section{HUMAN AND ANIMAL RIGHTS}

No animals were used in this research. All research procedures on humans followed were in accordance with the ethical standards of the committee responsible for human experimentation (institutional and national), and with the Helsinki Declaration of 1975, as revised in 2008.

\section{CONSENT FOR PUBLICATION}

All subjects provided written informed consent to be included in the study.

\section{STANDARD FOR REPORTING}

Strobe guidelines and methodology were followed to conduct the study.

\section{AVAILABILITY OF DATA AND MATERIALS}

The data sets analyzed during the current study are available from the corresponding author [L.K] upon request.

\section{FUNDING}

This study was supported by a grant from the Directorate of Research, University of Indonesia (Hibah TADOK 2019).

\section{CONFLICT OF INTEREST}

The authors declare no conflict of interest, financial or otherwise.

\section{ACKNOWLEDGEMENTS}

Declared none.

\section{REFERENCES}

[1] Oluboyo AO, Anaenye CV, Oluboyo BO, Ajayi FO. Assessment of the levels of parathyroid hormone, oestrogen and selected bone minerals in menopausal women. Am J Biomed Sci 2019; 2019: 189-94.

[2] Majumder MI, Harun MASI. Alveolar bone changes in postmenopausal osteopenic and osteoporosis women: An original research. Int J Dent Med Spec 2015; 2(2): 9-14.

[http://dx.doi.org/10.5958/2394-4196.2015.00010.2]

[3] Choudhary RK. Evaluation of parathyroid hormones, serum calcium and risk of fracture in premenopausal and postmenopausal women : A hospital based study. Ann Int Med Dent Res 2019; 5(3): 9-12. [http://dx.doi.org/10.21276/aimdr.2019.5.3.OR3]

[4] Mohammad AR, Hooper DA, Vermilyea SG, Mariotti A, Preshaw PM. An investigation of the relationship between systemic bone density and clinical periodontal status in post-menopausal Asian-American women. Int Dent J 2003; 53(3): 121-5. [http://dx.doi.org/10.1111/j.1875-595X.2003.tb00735.x] [PMID: 12873107]

[5] Usoro CAO, Onyeukwu CU, Nsonwu AC. Biochemical bone turnover markers in postmenopausal women in calabar municipality. Asian J Biochem 2007; 2: 130-5.

[http://dx.doi.org/10.3923/ajb.2007.130.135]

[6] Khatake PD, Jadhav SS, Afroz S. Relation between serum calcium level, bone mineral density and blood pressure in postmenopausal 
women. Int J Recent Trends Sci Technol 2013; 7(3): 86-8.

[7] Minisola S, Dionisi S, Pacitti MT, et al. Gender differences in serum markers of bone resorption in healthy subjects and patients with disorders affecting bone. Osteoporos Int 2002; 13(2): 171-5. [http://dx.doi.org/10.1007/s001980200009] [PMID: 11905526]

[8] Marya CM, Dhingra C. Effect of osteoporosis on oral health. Arch Med 2015; 8(21): 1-8.

[9] Van der Weijden F, Dell'Acqua F, Slot DE. Alveolar bone dimensional changes of post-extraction sockets in humans: A systematic review. J Clin Periodontol 2009; 36(12): 1048-58. [http://dx.doi.org/10.1111/j.1600-051X.2009.01482.x] [PMID: 19929956]

[10] Henriques PS, Pinto Neto AM. Association between tooth loss and bone mineral density in Brazilian postmenopausal women. J Clin Med Res 2011; 3(3): 118-23.

[http://dx.doi.org/10.4021/jocmr513w] [PMID: 21811542]

[11] Pan MY, Hsieh TC, Chen PH, Chen MY. Factors associated with tooth loss in postmenopausal women: A community-based cross-sectional study. Int J Environ Res Public Health 2019; 16(20): 1-8. [http://dx.doi.org/10.3390/ijerph16203945] [PMID: 31623275]

[12] Hakimi S, Mirghafurvand M. East Medditerranean Heal J 2010; 16: 1165-9.

[http://dx.doi.org/10.26719/2010.16.11.1165]

[13] Canger EM, Çelenk P. Radiographic evaluation of alveolar ridge heights of dentate and edentulous patients. Gerodontology 2012; 29(1): $17-23$.

[http://dx.doi.org/10.1111/j.1741-2358.2010.00391.x] [PMID: 20545771]

[14] Calciolari E, Donos N, Park JC, Petrie A, Mardas N. Panoramic measures for oral bone mass in detecting osteoporosis: A systematic review and meta-analysis. J Dent Res 2015; 94(3)(Suppl.): 17S-27S. [http://dx.doi.org/10.1177/0022034514554949] [PMID: 25365969]

[15] Demontiero O, Vidal C, Duque G. Aging and bone loss: New insights for the clinician. Ther Adv Musculoskelet Dis 2012; 4(2): 61-76. [http://dx.doi.org/10.1177/1759720X11430858] [PMID: 22870496]

[16] Franic D, Verdenik I. Risk factors for osteoporosis in postmenopausal women - from the point of view of primary care gynecologist. $\mathrm{Zdr}$ Varst 2018; 57(1): 33-8.

[http://dx.doi.org/10.2478/sjph-2018-0005] [PMID: 29651313]

[17] Esen I, Akturk Esen S, Cander S, Oz Gul O, Ocakoglu G, Erturk E. Causes of elevated parathyroid hormone levels in postmenopausal women. Eur Res J 2017 May; 1-10.

[http://dx.doi.org/10.18621/eurj.278518]

[18] Puspitadewi SR, et al. The relation of follicle stimulating hormone and estrogen to mandibular alveolar bone resorption in postmenopausal women. J Int Dent Med Res 2017; 10(3): 1-7.

[19] Puspitadewi SR, Wulandari P, Kusdhany LS, Masulili SLC, Bachtiar H. Relationship of age, body mass index, bone density, and menopause duration with alveolar bone resorption in postmenopausal women 2019; 19(1): 1-10.

[20] Sowers MR, Zheng H, Greendale GA, et al. Changes in bone resorption across the menopause transition: Effects of reproductive hormones, body size, and ethnicity. J Clin Endocrinol Metab 2013; 98(7): 2854-63.

[http://dx.doi.org/10.1210/jc.2012-4113] [PMID: 23666961]
[21] Nurumal MS, et al. Bone health status among postmenopausal women in malaysia. Int J Women's Health Reprod Sci 2019; 7(2): 169-73. [http://dx.doi.org/10.15296/ijwhr.2019.28]

[22] Bodic F, Hamel L, Lerouxel E, Baslé MF, Chappard D. Bone loss and teeth. Joint Bone Spine 2005; 72(3): 215-21.

[http://dx.doi.org/10.1016/j.jbspin.2004.03.007] [PMID: 15850992]

[23] Singh SV, Aggarwal H, Gupta V, Kumar P, Tripathi A. Measurements in mandibular pantomographic $\mathrm{x}$-rays and relation to skeletal mineral densitometric values. J Clin Densitom 2015; 1-7.

[http://dx.doi.org/10.1016/j.jocd.2015.03.004] [PMID: 25934028]

[24] Castro Alves R, Antunes Félix S, Rodriguez Archilla A. Is menopause associated with an increased risk of tooth loss in patients with periodontitis? Rev Port Estomatol Med Dentária e Cir Maxilofac 2013; 54(4): 210-6.

[http://dx.doi.org/10.1016/j.rpemd.2013.09.005]

[25] de Brito Galvao JF, Nagode LA, Schenck PA, Chew DJ. Calcitriol, calcidiol, parathyroid hormone, and fibroblast growth factor-23 interactions in chronic kidney disease. J Vet Emerg Crit Care (San Antonio) 2013; 23(2): 134-62.

[http://dx.doi.org/10.1111/vec.12036] [PMID: 23566108]

[26] Shoback D. Clinical practice. Hypoparathyroidism. N Engl J Med 2008; 359(4): 391-403.

[http://dx.doi.org/10.1056/NEJMcp0803050] [PMID: 18650515]

[27] Wein MN. Parathyroid hormone signaling in osteocytes. JBMR Plus 2017; 2(1): 22-30.

[http://dx.doi.org/10.1002/jbm4.10021] [PMID: 30283888]

[28] Silva BC, Bilezikian JP. Parathyroid hormone: Anabolic and catabolic actions on the skeleton. Curr Opin Pharmacol 2015; 22: 41-50. [http://dx.doi.org/10.1016/j.coph.2015.03.005] [PMID: 25854704]

[29] Khosla S, Atkinson EJ, Melton LJ III, Riggs BL. Effects of age and estrogen status on serum parathyroid hormone levels and biochemical markers of bone turnover in women: A population-based study. J Clin Endocrinol Metab 1997; 82(5): 1522-7. [http://dx.doi.org/10.1210/jc.82.5.1522] [PMID: 9141544]

[30] Fuller K, Owens JM, Chambers TJ. Induction of osteoclast formation by parathyroid hormone depends on an action on stromal cells. J Endocrinol 1998; 158(3): 341-50.

[http://dx.doi.org/10.1677/joe.0.1580341] [PMID: 9846163]

[31] Wang X, Wang Y, Dai X, et al. Effects of intermittent administration of parathyroid hormone (1-34) on bone differentiation in stromal precursor antigen-1 positive human periodontal ligament stem cells. Stem Cells Int 2016; 20164027542

[http://dx.doi.org/10.1155/2016/4027542] [PMID: 27069479]

[32] Yu B, et al. PTH induces differentiation of mesenchymal stem cells by enhancing bmp signaling. J Bone Miner Res 2012; 27(9): 1-22. [http://dx.doi.org/10.1002/jbmr.1663] [PMID: 22589223]

[33] Kim JH, Kim AR, Choi YH, et al. Intermittent PTH administration improves alveolar bone formation in type 1 diabetic rats with periodontitis. J Transl Med 2018; 16(1): 70.

[http://dx.doi.org/10.1186/s12967-018-1438-2] [PMID: 29544500]

[34] Finkelstein JS, Brockwell SE, Mehta V, et al. Bone mineral density changes during the menopause transition in a multiethnic cohort of women. J Clin Endocrinol Metab 2008; 93(3): 861-8. [http://dx.doi.org/10.1210/jc.2007-1876] [PMID: 18160467]

This is an open access article distributed under the terms of the Creative Commons Attribution 4.0 International Public License (CC-BY 4.0), a copy of which is available at: (https://creativecommons.org/licenses/by/4.0/legalcode). This license permits unrestricted use, distribution, and reproduction in any medium, provided the original author and source are credited. 